\title{
The journal in PubMed and the lessons of the SciELO/Fapesp seminar on journal performance
}

Milton Artur Ruiz

Editor-in-chief

Revista Brasileira de Hematologia e

Hemoterapia
Submitted: 11/23/2012

Accepted: 11/24/2012

\section{Corresponding author:}

Milton Artur Ruiz

Rua Catarina Nucci Parise, 760, Jardim Vivendas 15090-470 São José do Rio Preto, SP, Brazil

milruiz@yahoo.com.br
The third seminar, coordinated by SciELO and Fapesp, on the evaluation of the performance of Brazilian journals took place in September in São Paulo.

With the editors of most of the Brazilian journals linked to SciELO and Fapesp attending, the contribution of these two institutions was demonstrated in the event, as was the promising results observed since the first meeting held three years ago. It was reported that there has been an increase in the number of journals published in English. In the SciELO database, for example, the proportion increased from 33\% to $66 \%$ over three years and the progress of Brazil in the indexation of journals in the JCR/ISI/Thomson Reuters has been very expressive.

The increase in Brazilian scientific production with indexation of journals in the World of Science (WOS) of Thomson Reuters since 2005 is shown in Figures $1 \& 2^{(1)}$.

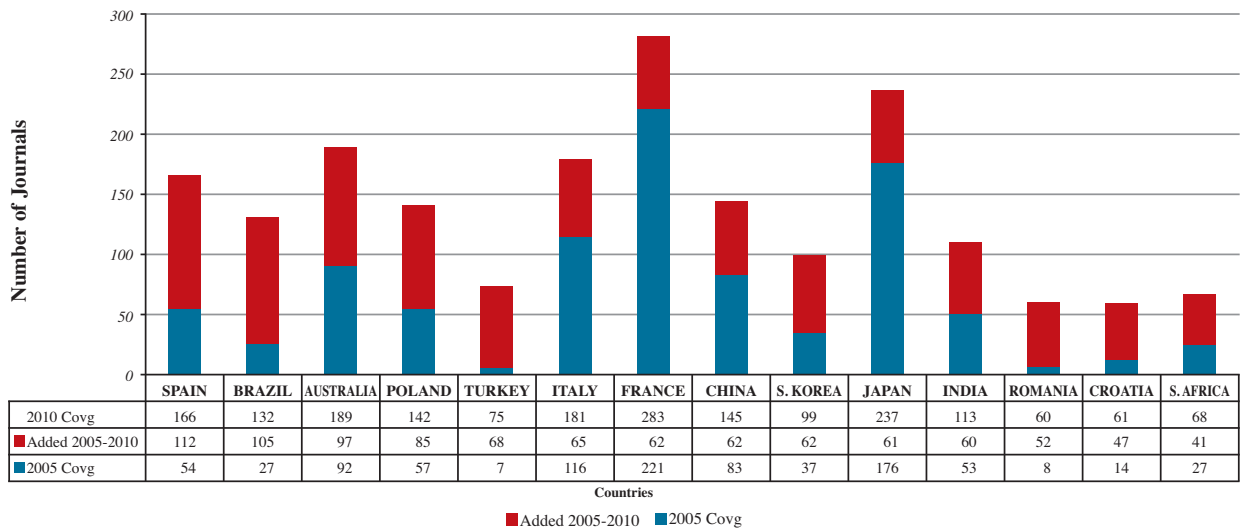

Figure 1 - 2005-2010: Countries that added over 40 titles to Web of Science

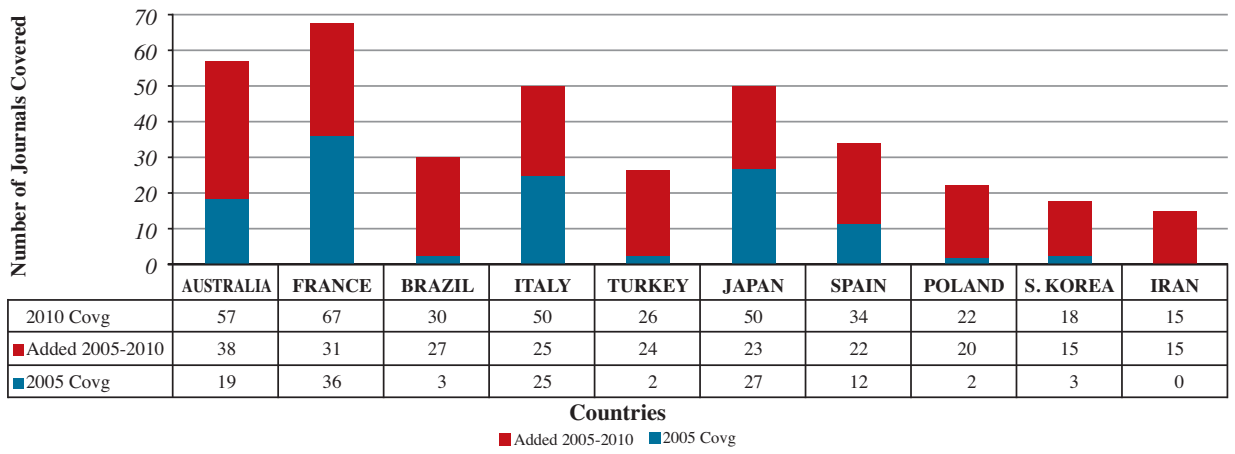

Figure 2 - 2005-2010: Clinical medicine - countries with greatest increase in coverage

For the first time in the area of health sciences, Brazilian journals have an Impact Factor (IF) higher than two and there is an increasing number of journals with IFs higher than one or that are close to this value.

In the event, the Editor-in-Chief of the journal Frontiers in Ecology and the Environment, Sue Silver gave a speech on the theme "Scientific journals: raising profiles, prospects and Impact Factors". 
With her experience with the implantation of the journal The LancetOncology,SueSilverlistedthedifferentmeasuresthatenabled her as editor of Frontiers in Ecology and the Environment to index the journal in the WOS in 2003 and to attain an IF of 3.32 by 2005 ; the current IF is 9.113. This IF is very high for medical journals. The magic formula to achieve this, as described by the Editor-in-Chief, is simply based on a professional organization of the journal, work and dedication at all levels of the editorial process and attaining a high-level of consultancy in the editorial, internal and marketing boards with the goal of deploying a judicious evaluation of the high-level scientific contributions that will be published. Sue Silver cited strategies on how to attract good authors and thus good papers for publication in the Frontiers in Ecology and the Environment. With this, the articles started to be cited and as a result there was an exponential increase in the IF as previously mentioned. This apparently trivial measure (that is difficult for some scientific institutions to understand) put Frontiers in Ecology and the Environment in second place of all journals in the area of environmental sciences worldwide. The Ecology Society of American that publishes the pleasant modern looking 'Frontiers in Ecology and the Environment' also publishes several other journals available both in print and on electronic media including with the use of new tools to access issues such as iPad.

Subsequently, in the SciELO/Fapesp meeting, several editors commented on their experiences and it became perfectly clear that indexation by JCR/ISI/Thomson Reuters and obtaining an IF is the Holy Grail of publishing, of scientific production and of the evaluation of researchers, especially in Brazil ${ }^{(2)}$. However, several publications have shown that the IF is not a good instrument to evaluate researchers and even the editor of Science has shown strong doubts in relation to this bibliometric index ${ }^{(2-5)}$.

With all the hype mixed with the excessive patriotism of a large country and of an emerging country expressed in the event, the Revista Brasileira de Hematologia e Hemoterapia has learned and followed the strategies of specialty journals that are less favored by funding agencies and by $\operatorname{CAPES}^{(7)}$. Even with the difficulties of a scientific journal that relies on its own finances, it is necessary to learn from the lessons of this and previous events: to overcome barriers, organize the journal's structure, to prepare a fearless and dedicated editorial staff, to expand the editorial board with international members, to start to publish in English and after two years in Lilacs, ExtraMed Scopus and SciELO become indexed in PubMed thereby giving definitive and international visibility to articles ${ }^{(8-11)}$. We consider this moment in the history of the journal to be an extremely special, but emblematic, one as achieving indexation in PubMed should just be considered another step in the evolution of the journal, a step that gives a greater degree of responsibility to the hematology and transfusion medicine community as a whole. We have an obligation to maintain the scientific journal and modernize it in order to adapt it for the culture shock that has already arrived with developments in electronic media and new manners to access and divulge journals.

We are only at the start.

\section{References}

1. Testa J. The globalization of Web of Science 2005-2010. 2011 [cited 2012 Nov 23] Available from: http://wokinfo.com/media/pdf/globalwosessay.pdf

2. Saha $S$, Saint $S$, Christakis DA. Impact factor: a valid measure of journal quality? J Med Libr Assoc. 2003;91(1):42-6.

3. Greenwood DC. Reliability of journal impact factor rankings. BMC Med Res Methodol. 2007;7:48.

4. Brown H. How impact factors changed medical publishing and science. BMJ. 2007;334(7593):561-4.

5. Ruiz MA, Greco OT, Braile DM. Journal Impact factor: this editorial academic and scientific influence. Rev Bras Cir Cardiovasc. 2009;24(3):273-8.

6. Pivetta M, Marques F. Ensinar ciência é preciso. Revista Pesquisa Fapesp. 2012;199: 28-33.

7. Ruiz MA. The Revista Brasileira de Hematologia e Hemoterapia now and discussion on the new classification of Brazilian journals. Rev Bras Hematol Hemoter. 2011;33(5): 325-6.

8. Ruiz MA. The journal's performance in 2011. Rev Bras Hematol Hemoter. 2011;33(6):399.

9. Ruiz MA. Countries emerging as major scientific powers. Rev Bras Hematol Hemoter 2011;33(3):169-71.

10. Ruiz MA. Challenge of emerging countries: barriers to get published. Rev Bras Hematol Hemoter. 2012;34(2):71-2.

11. Ruiz MA. Challenge of emerging countries: a relatively positive view for the future. Rev Bras Hematol Hemoter. 2012;34(3):173-4. 